\title{
Safety of Dihydroartemisinin-piperaquine Versus Artemether-lumefantrine for the Treatment of Uncomplicated Plasmodium Falciparum Malaria Among Children in Africa: A Systematic Review and Meta-analysis of Randomized Control Trials
}

Dawit Getachew Assefa ( $\square$ dawitgetachewa@gmail.com )

Dilla University College of Health Sciences https://orcid.org/0000-0002-9951-5762

\section{Gizachew Yesmaw}

Addis Ababa University College of Health Sciences

\section{Eyasu Makonnen}

Addis Ababa University College of Health Sciences

\section{Research Article}

Keywords: Uncomplicated Plasmodium falciparum, Adverse event, Pediatrics, Children, Safety, Randomized control trial, Artemisinin combination therapies, Dihydroartemisinin-piperaquine, Artemetherlumefantrine, Systematic review, and meta-analysis, Africa

Posted Date: August 4th, 2021

DOl: https://doi.org/10.21203/rs.3.rs-746101/v1

License: (c) (1) This work is licensed under a Creative Commons Attribution 4.0 International License. Read Full License 


\section{Abstract}

Background: The efficacies of artemisinin based combinations have been excellent in Africa, but little or no attention has been given to their safety. The aim of this review was to synthesize available evidence on the safety of dihydroartemisinin-piperaquine (DHA-PQ) compared to artemether-lumefantrine (AL) for the treatment of uncomplicated P.falciparum malaria among children in Africa.

Method: A systematic literature search was done to identify relevant articles from online databases PubMed/ MEDLINE, Embase, and Cochrane Center for Clinical Trial database (CENTRAL) for retrieving randomized control trials comparing safety of DHA-PQ and AL for treatment of uncomplicated P.falciparum malaria among children in Africa. The search was performed from August 2020 to 30 April 2021. Using Rev-Man software (V5.4.1), the extracted data from eligible studies were pooled as risk ratio (RR) with 95\% confidence interval (Cl).

Result: In this review, 18 studies were included, which involved 10,498 participants were included. Compared to AL, DHA-PQ was associated with a slightly higher frequency of early vomiting (RR $2.26,95 \%$ Cl 1.46 to 3.50; participants $=7796$; studies $=10 ; I^{2}=0 \%$, high quality of evidence), cough (RR $1.06,95 \%$ $\mathrm{Cl} 1.01$ to 1.11 ; participants $=8013$; studies $=13 ; I^{2}=0 \%$, high quality of evidence), and diarrhea (RR 1.16, $95 \% \mathrm{Cl} 1.03$ to 1.31 ; participants $=6841 ;$ studies $=11 ; I^{2}=8 \%$, high quality of evidence) were more frequent in DHA-PQ treatment arm.

Conclusion: From this review, it can be concluded that early vomiting, diarrhea, and cough were significantly more frequent in patients who were treated with the DHA-PQ than that of $A L$, and both drugs are well tolerated. More studies comparing AL with DHA-PQ are needed to determine the comparative safety of these drugs.

\section{Background}

Malaria is the major cause for vast majority of deaths among children under the age of five [1-3]. In 2019, an estimated 229 million cases were reported globally from 87 malaria endemic countries [3], of which 215 million cases were reported by the World Health Organization (WHO) African Region [3]. The risk of malaria infections among children aged under five years was higher in 2018, and $P$. falciparum parasite were responsible for an estimated 24 million malaria cases in African children [1].

All African counties, where $P$. falciparum malaria is endemic, have introduced the currently recommended Artemisinin-Based Combination Therapy (ACT) in the confirmed cases of $P$. falciparum malaria since 2004 [1]. The artemisinin component is active against the sexual stages of the parasite that facilitates transmission to mosquitos. The partner drug with a longer half-life eliminates the residual parasite over several weeks post treatment[4]. Artemisinin and partner drugs protect each other to prevent resistance development [5-8]. 
The efficacies of artemisinin based combinations have been excellent in Africa $[9,10]$ Artemetherlumefantrine (AL) is one of the most commonly used combinations in sub-Saharan Africa. It is the firstline treatment for uncomplicated malaria in several countries $[11,12]$. AL showed good safety and tolerability profile $[10,13,14]$. Hence, previous reviews reported mild or moderate severity adverse event of gastrointestinal and nervous systems in patients who were treated with AL [15] and prolongation of the QTc interval; pyrexia, early vomiting, and diarrhea were common in patients treated with DHA-PQ [16].

In the majority of African countries the first-line treatments for uncomplicated malaria are generally AL or $A S / A Q$, with $D H A-P Q$ as a second line in many countries $[11,12]$. Most of the previous studies have compared the efficacies of AL and other artemisinin-based combinations, but little or no attention has been given to their safety. Given the wide range of ACT available for treatment the malaria and their potential AEs, it is vital to compare their safety profiles. The aim of this review was to synthesize available evidence on the safety of dihydroartemisinin-piperaquine (DHA-PQ) compared to artemetherlumefantrine (AL) for the treatment of uncomplicated P.falciparum malaria among children in Africa.

\section{Methods}

This protocol has been registered at the International Prospective Register of Systematic Reviews (PROSPERO) database, ID: CRD42020200337 [17]. The methods and findings of the review have been reported according to the preferred reporting items for systematic reviews and meta-analyses (PRISMA 2020) [18].

\section{Eligibility Criteria}

The PICOS format was used to identify eligible studies [19].

\section{Participants}

\section{Children having uncomplicated falciparum malaria residing in Africa, regardless of gender, were included.}

\section{Interventions}

- A target dose (range) of $4(2-10) \mathrm{mg} / \mathrm{kg}$ bw per day dihydroartemisinin and 18 (16-27) $\mathrm{mg} / \mathrm{kg}$ bw per day piperaquine given once a day for 3 days for children weighing $\geq 25 \mathrm{~kg}$. The target doses and ranges for children weighing $<25 \mathrm{~kg}$ are $4(2.5-10) \mathrm{mg} / \mathrm{kg}$ bw per day dihydroartemisinin and 24 $(20-32) \mathrm{mg} / \mathrm{kg}$ bw per day piperaquine once a day for 3 days.

\section{Comparator}


- The 1:6 fixed dose combination tablet consisting artemether (20 mg) and lumefantrine $(120 \mathrm{mg})$. The body weight-adjusted dosages used have been: 25 to $35 \mathrm{~kg}, 3$ tablets per dose: 15 to $25 \mathrm{~kg}, 2$ tablets per dose; and $<15 \mathrm{~kg}$, 1 tablet.

- The medication administered twice a day for three days (total six doses). The first two doses taken eight hours apart; the third dose is taken after 24 hours the first and then every 12 hours on days 2 and 3.

\section{Outcome measures}

\section{Primary outcomes}

Adverse events including serious adverse events were also assessed. An adverse event (AE) was defined as any unfavorable, unintended sign, symptom, syndrome or disease that develops or worsens with the use of a medicinal product, regardless of whether it is related to the actual medicinal product. A serious $A E$ was defined as any untoward medical occurrence that at any dose; resulted in death; was life threatening; requiring hospitalization or prolongation of hospitalization; resulted in a persistent or significant disability or incapacity; or caused a congenital anomaly or birth defect [20].

\section{Studies}

Randomized controlled trials conducted in Africa which compared the safety of DHA-PQ versus AL for the treatment of uncomplicated falciparum malaria in children, written in English, and published between 2004 to April 2021 were included.

\section{Electronic searches}

A systematic literature search was done to identify relevant articles from online databases PubMed/ MEDLINE, Embase, and Cochrane Center for Clinical Trial database (CENTRAL). The search was limited to human trials, randomized control trials, and published between 2004 and April 2021. The search was done according to guidance provided in the Cochrane Handbook for Systematic Reviews of Interventions [19]. Additionally, we searched ClinicalTrials.gov and the WHO International Clinical Trials Registry Platform, and the US Food and Drug Administration (FDA) to search and assess ongoing or unpublished trials.

The search strategies in PubMed for the MeSH terms and text words was "Child"[Mesh]) AND "Plasmodium falciparum"[Mesh]) OR "Acute malaria" [Supplementary Concept]) OR "Artemether, Lumefantrine Drug Combination/therapeutic use"[Mesh]) OR "Lumefantrine"[Mesh]) OR "dihydroartemisinin" [Supplementary Concept]) OR "piperaquine" [Supplementary Concept]) OR ( "Randomized Controlled Trial" [Publication Type] OR "Randomized Controlled Trials as Topic"[Mesh] OR 
"Controlled Clinical Trial" [Publication Type] )) AND ( "Drug Therapy"[Mesh] OR "Drug Therapy, Combination"[Mesh] OR "drug therapy" [Subheading] )) AND ( "Africa"[Mesh] OR "Africa South of the Sahara"[Mesh] OR "Africa, Western"[Mesh] OR "Africa, Southern"[Mesh] OR "Africa, Northern"[Mesh] OR "Africa, Eastern"[Mesh] OR "Africa, Central"[Mesh] . The searching strategies for Cochrane Center for Clinical Trial database (CENTRAL) and Embase are found in Additional file $S 1$.

\section{Study selection, data collection, and data analysis}

The Cochrane Handbook for Systematic Reviews of Interventions [21] was followed. Furthermore, the software package provided by Cochrane (RevMan 5.4.1) was used. To import the research articles from the electronic databases and remove duplicates, ENDNOTE software version X7 was used. Two authors independently review the results of the literature search and obtained full-text copies of all potentially relevant trials. Disagreements were resolved through discussion. When clarification was necessary, the trial authors were contacted for further information. The screening and selection process was reported in a PRISMA flow chart Fig. 1.

\section{Data extraction and management}

The title and abstract was produced from the electronic search, and was independently screened by two authors based on RCTs that were assessed human P.falciparum malaria. The information collected were trial characteristics including methods, participants, interventions, and outcomes as well as data on dose and drug ratios of the combinations. Also, relevant information such as title, journal, year of publication, publication status, study design, study setting, malaria transmission intensity, follow-up period, sample size, funding of the trial or sources of support, baseline characteristics of study subjects and adverse events including serious AEs were extracted from each article using the well-prepared extraction format in the form of a table adapted from Cochrane and modified to make suitable for this study.

Furthermore, the number of participants randomized, and the number analyzed in each treatment group for each outcome were also collected. One author independently extracted data and information collected was cross-checked by another investigator. The number of participants experiencing the event and the number of participants in each treatment group were documented.

\section{Assessment of risk of bias in included studies}

The risk of bias for each trial was evaluated by two review authors independently using the Cochrane Collaboration's tool for assessing the 'Risk of bias' [19]. The risks were classified as high risk, unclear risk, and low risk.

\section{Measures of treatment effect}

The main outcomes in this review were total of patients who experienced one or more adverse events. A number of patients with AEs from the studies were combined and presented using risk rations. We used Risk ratios accompanied by $95 \%$ Cls. 


\section{Unit of analysis issues}

Participants were included according to the treatment group of the randomized clinical trials.

\section{Assessment of heterogeneity}

Heterogeneity among the included trials was assessed by inspecting the forest plots and the Cochrane $Q$ and $I^{2}$ statistic used to measure heterogeneity among the trials in each analysis, the $\mathrm{Chi}^{2}$ test with a $\mathrm{P}<0.10$ to indicate statistical significance was used, and the results were interpreted following Cochrane Handbook for Systematic Reviews of Interventions Version 6.0, Chapter 10: Analyzing data and undertaking meta-analyses [22].

- $0 \%$ to $40 \%$ : might not be important;

- $30 \%$ to $60 \%$ : may show moderate heterogeneity;

- $50 \%$ to $90 \%$ : may show substantial heterogeneity;

- $75 \%$ to $100 \%$ : considerable heterogeneity.

\section{Assessment of reporting bias}

\section{To assess the possibility of publication bias, funnel plots for asymmetry (Egger's test $\mathrm{P}<0.05$ ) were used.}

Data synthesis

The meta-analyses was done consistent with the recommendations of Cochrane [21]. To aid interpretation, identity codes were given to included trials together with the first author, year of publication, and three first letter of the country where the trial being conducted. Trials were shown in forest plots in chronological order of the year the trials were published. A random-effects model was used, as trials were done by different researchers, operating independently, and it could be implausible that all the trials had functionally equivalence, with a common effect estimate.

Sensitivity analysis 
To investigate the strength of the methodology used in the primary analysis, a series of sensitivity analyses were conducted. To restore the integrity of the randomization process, the following steps were used: adding and excluding trials which were classified as high risk for bias back into the analysis in a stepwise fashion, and to assess the influence of small-study effects on the results of our meta-analysis, fixed-effect and random-effects estimates of the intervention effect were compared.

\section{Quality of evidence}

Quality of evidence was assessed using GRADE criteria and the GRADE pro software [23]. The results were presented in a 'Summary of Findings' table. Randomized trials are initially categorized as high quality but downgraded after assessment of five criteria [24]. The levels of evidence were defined as 'high', 'moderate', 'low', or 'very low'. The recommendations of Section 8.5 and Chapter 13 of the Cochrane Handbook for Systematic Reviews of Interventions was followed [25]. The imprecision was judged based on the optimal information size criteria and $\mathrm{Cl}$ [26].

\section{Results}

A total of 3211 studies through the databases were searched, of which 49 full-text trials for eligibility were assessed and 18 of them fulfilled the inclusion criteria for meta-analysis and for qualitative analysis Fig. 1.

\section{Characteristics of included studies}

In this review, 18 studies were included, which enrolled 10,498 participants with uncomplicated $P$. falciparum malaria were included, Additional file S 2.

\section{Characteristics of exculded studies}

Thirty one studies were excluded with reason, Additional file S 3 .

\section{Methodological quality and risk of bias}

The 'Risk of bias' assessments were summarized in Fig. 2.

\section{Adverse events}

\section{Gastrointestinal adverse events}




\section{Early vomiting}

The relative risk of early vomiting in patients treated with the DHA-PQ was higher than AL (RR 2.26, 95\% $\mathrm{Cl} 1.46$ to 3.50 ; participants $=7796$; studies $=10 ; I^{2}=0 \%$, high quality of evidence, Fig. 3 ).

\section{Publication Bias}

The funnel plot showed that all studies lied symmetrically around the pooled effect estimate implying that there was no publication bias ( $P=0.5$, Additional file $S 4)$.

\section{Diarrhea}

Similarly, the relative risk of early vomiting in patients treated with the DHA-PQ was higher than AL (RR $1.16,95 \% \mathrm{Cl} 1.03$ to 1.31 ; participants $=6841$; studies $=11 ; I^{2}=8 \%$, high quality of evidence, Fig. 3 ).

\section{Publication bias}

The funnel plot showed that all studies lied symmetrically around the pooled effect estimate implying that there was no publication bias ( $P=0.9$, Additional file $S$ ).

\section{Other gastrointestinal adverse events}

The risk of vomiting did not have significant difference between the two treatment groups (RR 1.02, 95\% $\mathrm{Cl} 0.87$ to 1.19 ; participants $=8789$; studies $=13 ; I^{2}=20 \%$, high quality of evidence, Fig. 4). Similarly, there was no significant difference between the two treatment groups on the relative risk of anorexia (RR 0.95, $95 \% \mathrm{Cl} 0.84$ to 1.07 ; participants $=6841$; studies $=11 ;\left.\right|^{2}=0 \%$, high quality of evidence), abdominal pain (RR 0.80, 95\% Cl 0.57 to 1.11; participants $=2732$; studies $=8 ; I^{2}=53 \%$, high quality of evidence, Fig. 4), gastroenteritis (RR $0.57,95 \% \mathrm{Cl} 0.19$ to 1.68 ; participants $=469$, and loss of appetite (RR $2.06,95 \% \mathrm{Cl}$ 0.52 to 8.14 ; participants $=469$; studies $=1,[27]$ ).

Cardio-respiratory adverse events

\section{Cough}

Cough was the most common cardio-respiratory adverse event, and significantly higher number of participants from DHA-PQ treatment group experienced cough (RR 1.06, 95\% Cl 1.01 to 1.11; participants $=8013$; studies $=13 ; I^{2}=0 \%$, high quality of evidence, Fig.5).

\section{Publication bias}

The funnel plot shows that all studies lie symmetrically around the pooled effect estimate implying that there was no publication bias ( $P=0.84$, Additional file $S 6$ ). 


\section{Other cardiorespiratory and hematological adverse events}

The relative risk of developing coryza didn't have significant difference between the two treatment groups (RR 1.00, 95\% Cl 0.92 to 1.10; participants $=832$; studies $=2 ;\left.\right|^{2}=0 \%$, Fig.5). In addition, the relative risk of respiratory adverse events such as rhinorrhea, respiratory tract infection, rhinitis, and pallor didn't have significant difference between the two treatment groups (RR 1.59, 95\% $\mathrm{Cl} 0.89$ to 2.83; participants $=442$; studies $=1$, [28] $),($ RR 1.23, 95\% Cl 0.59 to 2.57; participants $=299$; studies = 1, [29] $)$, $(\mathrm{RR} 3.35,95 \% \mathrm{Cl} 1.11$ to 10.12 ; participants $=469$; studies $=1$, [27]), $95 \% \mathrm{Cl} 0.91$ to 1.92 ; participants $=$ 1548; studies $=1,[30])$. Similarly, the relative risk of cardiac adverse events like QTc interval prolongation (Fridericia's correction and Bazett's correction) didn't also have significant difference between the two treatment groups (RR 0.98, 95\% Cl 0.51 to 1.90; participants $=1548$; studies $=1$, [30] and $(\mathrm{RR} 0.98,95 \% \mathrm{Cl}$ 0.09 to 10.81 and $\mathrm{RR} 1.32,95 \% \mathrm{Cl} 0.91$ to 1.92 , participants= 1548 , studies $=1$, [30]).

\section{Neuropsychiatry adverse event}

\section{weakness/malaise}

The relative risk of developing weakness or malaise was not significantly different between the two treatment groups (RR $0.88,95 \% \mathrm{Cl} 0.74$ to 1.03 ; participants $=3407$; studies $=8 ; I^{2}=0 \%$, high quality of evidence, Fig. 6). Also, the relative risk of headache was not significantly different between the two treatment groups (RR 0.81, 95\% Cl 0.47 to 1.38; participants = 598; studies $=3 ; I^{2}=72 \%$, Fig. 6 ).

\section{Musculoskeletal/dermatological adverse events}

Pruritus was the most common dermatological adverse event, and the relative risk of developing pruritus was not significantly different between the two treatment groups (RR $1.00,95 \% \mathrm{Cl} 0.56$ to 1.78 ; participants $=1952 ;$ studies $=5 ; I^{2}=49 \%$, moderate quality of evidence, Fig. 7$)$. Also, the relative risk of developing skin rash was not significantly different between the two treatment groups (RR $1.40,95 \% \mathrm{Cl}$ 0.99 to 1.96 ; participants $=1720$; studies $=3 ; 1^{2}=0 \%$, Fig. 7 ).

\section{Other Musculoskeletal/dermatological adverse events}

The relative risk of musculoskeletal or dermatological adverse events such as: skin and subcutaneous disorder, urticarial, hypersensitivity, pyoderma, conjunctivitis, joint pain, tinea-capitis, itchiness, frunculosis was not significantly different between the two treatment groups (RR 1.19, 95\% Cl 0.78 to 1.80; participants $=1548$; studies $=1,[30]),(R R 0.25,95 \% \mathrm{Cl} 0.02$ to $2.70 ;$ participants $=1548 ;$ studies $=1$, [30] $)$, (RR 0.98, 95\% Cl 0.09 to 10.81; participants $=1548$; studies = 1, [30]), (RR 1.00, 95\% Cl 0.33 to 3.05; participants $=442 ;$ studies $=1,[28]),(\operatorname{RR~} 0.47,95 \% \mathrm{Cl} 0.19$ to $1.12 ;$ participants $=442$; studies $=1,[28])$, 
(RR 0.49, 95\% Cl 0.07 to 3.46; participants = 418; studies = 1, [31]), $(\mathrm{RR} 1.24,95 \% \mathrm{Cl} 0.54$ to 2.81; participants $=469 ;$ studies $=1$, [27] $),(\operatorname{RR} 0.34,95 \% \mathrm{Cl} 0.01$ to 8.22; participants $=703$; studies $=1,[32])$ and (RR 3.03, 95\% Cl 0.12 to 74.02; participants $=703$; studies $=1$, [32]), respectively.

\section{Other adverse events}

\section{Pyrexia}

The relative risk of pyrexia was the same in both treatment groups ( $\mathrm{RR} 0.94,95 \% \mathrm{Cl} 0.85$ to 1.04 ; participants $=4620$; studies $=6 ; \mathrm{I}^{2}=0 \%$, Fig. 8). Similarly, the relative risk of otitis media was the same in both treatment groups (RR $0.66,95 \% \mathrm{Cl} 0.23$ to 1.91 ; participants $=1157$; studies $=2 ;\left.\right|^{2}=0 \%$, Fig. 8 ).

\section{Serious adverse event}

Fourteen studies reported 59 serious adverse events in the DHA-PQ and 35 in the AL treatment groups. However, the distributions of serious adverse events were not significantly different in the two treatment groups (RR 1.27, 95\% Cl 0.83 to 1.96; participants $=9558$; studies $=14 ; I^{2}=0 \%$, high quality of evidence, Fig. 9). Eight deaths were reported from two multi-center trials, and the cause of death for seven of them was sepsis, severe malaria, and severe diarrhea. But, the causal relationship of the study drug and death of one participant didn't rule out. All serious adverse events were likely a consequence of malaria and judged to be unrelated to study medications.

\section{Publication bias}

The funnel plot showed that all studies lied symmetrically around the pooled effect estimate implying that there was no publication bias ( $P=0.50$, Additional file $S 7$ ).

\section{Quality of the evidence}

We assessed the quality of the evidence in this review using the GRADE approach and presented the evidence in three summary of findings tables for safety (Summary of findings for the main comparison; Additional file S 8). The quality of evidence on comparative adverse effects and serious adverse events; early vomiting, diarrhea, and cough were slightly more frequent in the DHA-PQ arm (high quality of evidence). Generally, the quality of evidence of safety of the two treatments was high quality.

\section{Discussion}

In this study both drugs were well tolerated by children. There were comparable occurrences of adverse events in both treatment arms. But, early vomiting, diarrhea, and cough were common were significantly 
more frequent in patients who were treated with the DHA-PQ than that of AL (high quality of evidence). All serious adverse events were not related to study medications. Eight deaths have occurred in all studies. But, all serious adverse events were consistent with malaria symptoms and judged to be unrelated to study medication.

As also seen in one study from Papua New Guinea, the overall frequency of adverse events were slightly higher in DHA-PQ treatment arm than that of AL [33]. However, Cough was more frequent in patients who were treated with $\mathrm{AL}$, but headache and runny nose were common in DHA-PQ treatment group [33]. A recent review on the efficacy and safety of the two ACT's also reported that cough, anorexia, diarrhea, and vomiting were the most common adverse events. In this review more patients from DHA-PQ treatment arm had cough than that of AL [34] and similarly, gastrointestinal adverse events were more frequent in patients who were treated with DHA-PQ in another study done in South East Asia and Africa [35-38]. Studies from the Thailand-Myanmar border [39, 40] and elsewhere in Africa [41-44] have reported that DHA-PQ cause drug induced electrocardiographic QT prolongation. Regardless of the treatment groups, most of these adverse events are associated with age ( $\leq 18$ years) [37], efavirenz-based ART [37], efavirenz-based ART [45], and administration of DHA-PQ with food could increase piperaquine exposure and it needs to be administered in fasting state [40-42].

Most of the RCTs reported AEs rather than adverse reactions of the antimalarial drugs. This made it difficult to determine the causal relationship between the antimalarial drugs and the AEs. It was, therefore, difficult to determine whether an adverse event is symptomatic of the disease or drug related. In some other studies, safety reporting was either selective or inadequate, with some authors failing to indicate the severity of AEs. Some of these limitations have been identified in studies evaluating the quality of safety reporting in RCTs.

\section{Conclusions}

From this review, it can be concluded that early vomiting, diarrhea, and cough were significantly more frequent in patients who were treated with the DHA-PQ than that of $A L$, and both drugs are well tolerated. More studies comparing AL with DHA-PQ are needed to determine the comparative safety of these drugs.

\section{Abbreviations}

$\mathbf{A E}=$ Adverse event, $\mathbf{A C T}=$ Artemisinin-based combination therapy, $\mathbf{A L}=$ artemether-lumefantrine, $\mathrm{ART}=$ Antiretroviral therapy, BW= Body weight, CENTRAL=Cochrane Central Register of Controlled Trials, $\mathrm{Cl}=$ confidence interval, DHA-PQ= dihydroartemisinin-piperaquine, $\mathrm{GADE}=$ Grading of Recommendations, Assessment, Development, and Evaluations, PICO= Population, Intervention, Comparison, and outcome, PRISMA=Preferred Reporting Items for Systematic Reviews and Meta-Analyses, RCTs= Randomized control trials, $\mathrm{RR}=$ risk ratio, and $\mathbf{W H O}=$ World Health Organization.

\section{Declarations}


Ethics approval and consent to participate

Not applicable.

Consent for publication

Not applicable.

Availability of data and materials

All relevant data are within the manuscript and its supporting information files.

\section{Competing of interest}

We declare that they have no competing interests.

Funding

This review was funded by Center for Innovative Drugs and Therapeutic Trial for Africa (CDT-Africa), Addis Ababa University.

\section{Authors' contributions}

DGA developed the protocol as used in [7]. For this review, DGA reviewed the reference list, extracted data, and entered it into Review Manager (Rev-Man 5.4.1). DGA conducted the analyses, constructed summary of findings tables, and evaluated the quality of evidence using the GRADE approach. EM and GY were responsible for the quality assessment and review of the study. All authors reviewed and edited the manuscript.

\section{Acknowledgments}

We would like to express our gratitude to the Center for Innovative Drug Development and Therapeutic Trials for Africa (CDT-Africa), College of Health Sciences, Addis Ababa University, for funding the study.

\section{References}

1. WHO. World Malaria Report 2019: Geneva, World Health Organization, 2019 [Available from: https://www.who.int/malaria/publications/world-malaria-report-2019/en/]

2. WHO. Guidelines for treatment of malaria, 3rd edn. Geneva, World Health Organization, 2015 [Available from: https://www.who.int/malaria/publications/atoz/9789241549127/en/]

3. World malaria report 2020: 20 years of global progress and challenges. Geneva: World Health Organization; 2020. [Available from: https://www.who.int/teams/global-malariaprogramme/reports/world-malaria-report-2020] 
4. Bretscher MT, Griffin JT, Hugo P, Baker M, Ghani A, Okell L: A comparison of the duration of posttreatment protection of artemether-lumefantrine, dihydroartemisinin-piperaquine and artesunateamodiaquine for the treatment of uncomplicated malaria. Malaria Journal 2014, 13:P19-P19.

5. Sinclair D, Zani B, Donegan S, Olliaro P, Garner P: Artemisinin-based combination therapy for treating uncomplicated malaria. Cochrane Database Syst Rev 2009, 2009:Cd007483.

6. WHO. World Malaria Report 2014. Geneva, World Health Organization, 2014 [Available from: https://www.who.int/malaria/publications/world_malaria_report_2014/en]

7. Zani B, Gathu M, Donegan S, Olliaro PL, Sinclair D: Dihydroartemisinin-piperaquine for treating uncomplicated Plasmodium falciparum malaria. Cochrane Database Syst Rev 2014, 2014:Cd010927.

8. Fairhurst RM, Dondorp AM: Artemisinin-Resistant Plasmodium falciparum Malaria. Microbiol Spectr 2016, 4.

9. Plucinski MM, Dimbu PR, Macaia AP, Ferreira CM, Samutondo C, Quivinja J, et al: Efficacy of artemether-lumefantrine, artesunate-amodiaquine, and dihydroartemisinin-piperaquine for treatment of uncomplicated Plasmodium falciparum malaria in Angola, 2015. Malar J 2017, 16:62.

10. Davlantes E, Dimbu PR, Ferreira CM, Florinda Joao M, Pode D, Félix J, et al: Efficacy and safety of artemether-lumefantrine, artesunate-amodiaquine, and dihydroartemisinin-piperaquine for the treatment of uncomplicated Plasmodium falciparum malaria in three provinces in Angola, 2017. Malar J 2018, 17:144.

11. WHO: World Malaria Report 2017. World Health Organization,Geneva, Switzerland Avilable at: https://wwwwhoint/malaria/publications/world-malaria-report-2017/report/en/November 2017.

12. Health TRoUMo: Uganda Clinical Guidelines. National Guidelines for Management of Common Conditions. Available from: http://libraryhealthgoug/publications/guidelines/uganda-clinical-guidelines2016 2016:195-199.

13. Makanga M, Bassat Q, Falade CO, Premji ZG, Krudsood S, Hunt P, et al: Efficacy and Safety of Artemether-Lumefantrine in the Treatment of Acute, Uncomplicated Plasmodium falciparum Malaria: A Pooled Analysis. Am J Trop Med Hyg 2011, 85:793-804.

14. Ebstie YA, Zeynudin A, Belachew T, Desalegn Z, Suleman S: Assessment of therapeutic efficacy and safety of artemether-lumefantrine (Coartem $\AA$ ) in the treatment of uncomplicated Plasmodium falciparum malaria patients in Bahir Dar district, Northwest Ethiopia: an observational cohort study. Malar J 2015, 14.

15. Falade C, Manyando C: Safety profile of Coartem ${ }^{\circledR}$ : the evidence base. Malar J 2009, 8:S6. 
16. Agency EM: Eurartesim (dihydroartemisinin/piperaquine) $20 \mathrm{mg} / \mathbf{1 6 0} \mathrm{mg}$ and $\mathbf{4 0} \mathrm{mg} / 320 \mathrm{mg}$ filmcoated tablets: EU summary of product characteristics [online]

17. Systematic review and meta-analysis of the efficacy and safety of Dihydroartemisinin Piperaquine versus Artemether-Lumefantrine for the treatment of uncomplicated falciparum malaria in African children. PROSPERO 2020 [Available from: https://www.crd.york.ac.uk/prospero/display_record.php? ID =CRD42020200337]

18. Page MJ, McKenzie JE, Bossuyt PM, Boutron I, Hoffmann TC, Mulrow CD, et al: The PRISMA 2020 statement: an updated guideline for reporting systematic reviews. BMJ 2021, 372:n71.

19. Higgins JPT, Green S., Eds. Cochrane Handbook for Systematic Reviews of Interventions, 2011 [Available from: www.cochrane-handbook.org]

20. WHO. Methods for surveillance of antimalarial drug efficacy. Geneva, World Health Organization, 2009 [Available from: https://www.who.int/malaria/publications/atoz/9789241597531/en/]

21. Higgins JPT, Thomas J, Chandler J, Cumpston M, Li T, Page MJ, Welch VA, et al. Cochrane Handbook for Systematic Reviews of Interventions version 6.2 (updated February 2021). Cochrane, 2021 [Available from: www.training.cochrane.org/handbook]

22. Deeks JJ, Higgins JPT, Altman DG. Chapter 10: Analysing data and undertaking meta-analyses. In: Higgins JPT, Thomas J, Chandler J, Cumpston M, Li T, Page MJ, et al., Eds. Cochrane Handbook for Systematic Reviews of Interventions version 6.2 (updated February 2021). Cochrane, 2021 [Available from: www.training.cochrane.org/handbook]

23. McMaster University GRADEproGDT. McMasterUniversity (developed by Evidence Prime), 2020 [Available from: https://gradepro.org/]

24. Schünemann, Brożek, Guyatt, Oxman. Introduction to GRADE Handbook (Handbook for grading the quality of evidence and the strength of recommendations using the GRADE approach), 2013 [Available from: https://gradepro.org]

25. HigginsJPT, SavovicJ, PageMJ, ElbersRG, Sterne JAC . Chapter 8: Assessing risk of bias in a randomized trial.Cochrane Handbook for Systematic Reviews of Interventions version 6.0 (updated July 2019). Cochrane, 2019 [Available from: www.training.cochrane.org/handbook]

26. Guyatt GH, Oxman AD, Kunz R, Brozek J, Alonso-Coello P, Rind D, et al: GRADE guidelines 6. Rating the quality of evidence-imprecision. J Clin Epidemiol 2011, 64:1283-1293. 
27. Ogutu BR, Onyango KO, Koskei N, Omondi EK, Ongecha JM, Otieno GA, et al: Efficacy and safety of artemether-lumefantrine and dihydroartemisinin-piperaquine in the treatment of uncomplicated Plasmodium falciparum malaria in Kenyan children aged less than five years: results of an open-label, randomized, single-centre study. Malar J 2014, 13:33.

28. Grandesso F, Guindo O, Woi Messe L, Makarimi R, Traore A, Dama S, et al: Efficacy of artesunateamodiaquine, dihydroartemisinin-piperaquine and artemether-lumefantrine for the treatment of uncomplicated Plasmodium falciparum malaria in Maradi, Niger. Malar J 2018, 17:52.

29. Nambozi M, Van Geertruyden JP, Hachizovu S, Chaponda M, Mukwamataba D, Mulenga M, et al: Safety and efficacy of dihydroartemisinin-piperaquine versus artemether-lumefantrine in the treatment of uncomplicated Plasmodium falciparum malaria in Zambian children. Malar J 2011, 10:50.

30. Bassat Q, Mulenga M, Tinto H, Piola P, Borrmann S, Menendez C, et al: Dihydroartemisininpiperaquine and artemether-lumefantrine for treating uncomplicated malaria in African children: a randomised, non-inferiority trial. PLoS One 2009, 4:e7871.

31. Nji AM, Ali IM, Moyeh MN, Ngongang EO, Ekollo AM, Chedjou JP, et al: Randomized non-inferiority and safety trial of dihydroartemisin-piperaquine and artesunate-amodiaquine versus artemetherlumefantrine in the treatment of uncomplicated Plasmodium falciparum malaria in Cameroonian children. Malar J 2015, 14:27.

32. Gansané A, Moriarty LF, Ménard D, Yerbanga I, Ouedraogo E, Sondo P, et al: Anti-malarial efficacy and resistance monitoring of artemether-lumefantrine and dihydroartemisinin-piperaquine shows inadequate efficacy in children in Burkina Faso, 2017-2018. Malaria Journal 2021, 20.

33. Tavul L, Hetzel MW, Teliki A, Walsh D, Kiniboro B, Rare L, et al: Efficacy of artemether-lumefantrine and dihydroartemisinin-piperaquine for the treatment of uncomplicated malaria in Papua New Guinea. Malaria Journal 2018, 17:350.

34. Assefa DG, Zeleke ED, Bekele D, Tesfahunei HA, Getachew E, Joseph M, et al: Efficacy and safety of dihydroartemisinin-piperaquine versus artemether-lumefantrine for treatment of uncomplicated Plasmodium falciparum malaria in Ugandan children: a systematic review and meta-analysis of randomized control trials. Malaria Journal 2021, 20:174.

35. Myint HY, Ashley EA, Day NP, Nosten F, White NJ: Efficacy and safety of dihydroartemisininpiperaquine. Trans R Soc Trop Med Hyg 2007, 101:858-866.

36. Kakolwa MA, Mahende MK, Ishengoma DS, Mandara Cl, Ngasala B, Kamugisha E, et al: Efficacy and safety of artemisinin-based combination therapy, and molecular markers for artemisinin and piperaquine resistance in Mainland Tanzania. Malaria Journal 2018, 17:369. 
37. Creek D, Bigira V, Arinaitwe E, Wanzira H, Kakuru A, Tappero J, et al: Increased risk of early vomiting among infants and young children treated with dihydroartemisinin-piperaquine compared with artemether-lumefantrine for uncomplicated malaria. Am J Trop Med Hyg 2010, 83:873-875.

38. Yavo W, Faye B, Kuete T, Djohan V, Oga SA, Kassi RR, et al: Multicentric assessment of the efficacy and tolerability of dihydroartemisinin-piperaquine compared to artemether-lumefantrine in the treatment of uncomplicated Plasmodium falciparum malaria in sub-Saharan Africa. Malar J 2011, 10:198.

39. Saito M, Yotyingaphiram W, Cargill Z, Gilder ME, Min AM, Phyo AP, et al: Electrocardiographic effects of four antimalarials for pregnant women with uncomplicated malaria on the Thailand-Myanmar border: a randomised controlled trial. Antimicrobial agents and chemotherapy 2021.

40. Manning J, Vanachayangkul P, Lon C, Spring M, So M, Sea D, et al: Randomized, double-blind, placebo-controlled clinical trial of a two-day regimen of dihydroartemisinin-piperaquine for malaria prevention halted for concern over prolonged corrected QT interval. Antimicrobial Agents and Chemotherapy 2014, 58:6056-6067.

41. Funck-Brentano C, Bacchieri A, Valentini G, Pace S, Tommasini S, Voiriot P, et al: Effects of Dihydroartemisinin-Piperaquine Phosphate and Artemether-Lumefantrine on QTc Interval Prolongation. Sci Rep 2019, 9:777.

42. Oduro AR, Owusu-Agyei S, Gyapong M, Osei I, Adjei A, Yawson A, et al: Post-licensure safety evaluation of dihydroartemisinin piperaquine in the three major ecological zones across Ghana. PLOS ONE 2017, 12.

43. Kabanywanyi AM, Baiden R, Ali AM, Mahende MK, Ogutu BR, Oduro A, et al: Multi-country evaluation of safety of dihydroartemisinin/piperaquine post-licensure in african public hospitals with electrocardiograms. PLOS ONE 2016, 11.

44. Mhamilawa LE, Wikström S, Mmbando BP, Ngasala B, Mårtensson A: Electrocardiographic safety evaluation of extended artemether-lumefantrine treatment in patients with uncomplicated Plasmodium falciparum malaria in Bagamoyo District, Tanzania. Malaria Journal 2020, 19.

45. Sevene E, Banda CG, Mukaka M, Maculuve S, Macuacua S, Vala A, et al: Efficacy and safety of dihydroartemisinin-piperaquine for treatment of Plasmodium falciparum uncomplicated malaria in adult patients on antiretroviral therapy in Malawi and Mozambique: an open label non-randomized interventional trial. Malaria Journal 2019, 18:277.

\section{Figures}




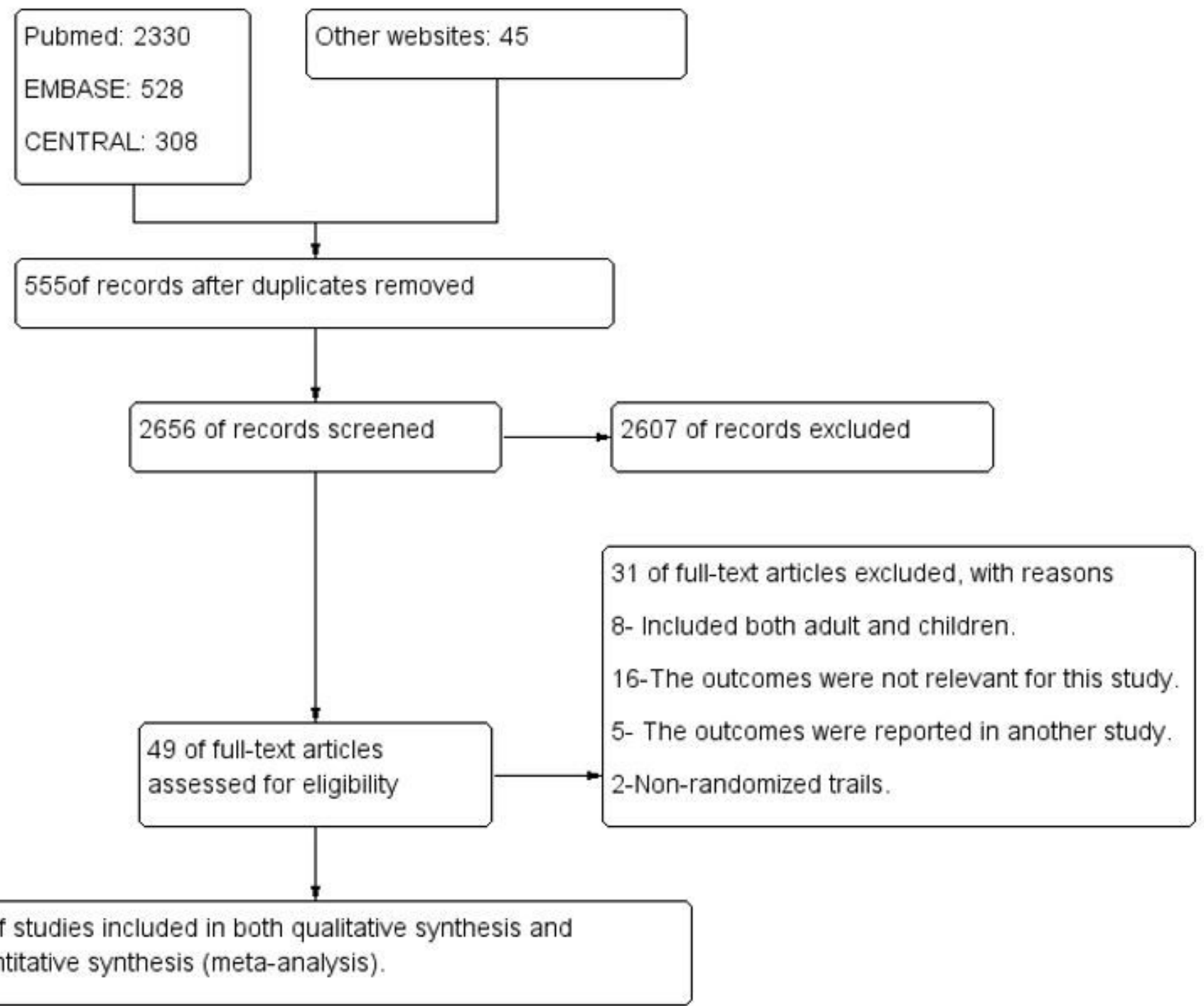

Figure 1

PRISMA study flow diagram of the study. 


\begin{tabular}{|c|c|c|c|c|c|c|c|}
\hline & 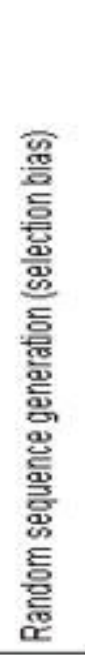 & 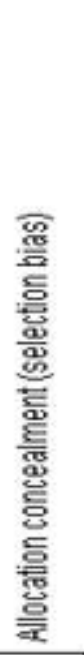 & 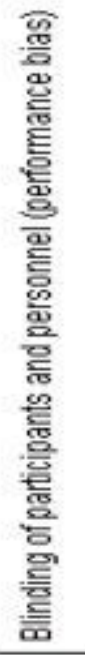 & 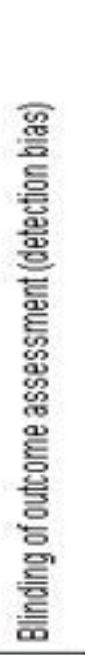 & 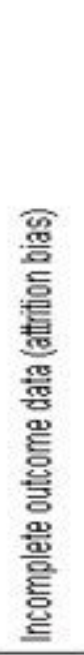 & 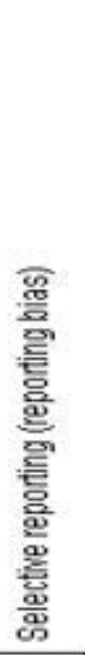 & $\begin{array}{l}\text { 용 } \\
\text { 总 } \\
\text { 言 } \\
\end{array}$ \\
\hline 4ABC-2011-AFR & 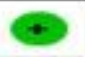 & 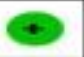 & $\oplus$ & $\oplus$ & $\oplus$ & $\oplus$ & $\oplus$ \\
\hline Aganwal-2013-KEN & $\rightarrow$ & $?$ & $?$ & $\oplus$ & $B$ & $\rightarrow$ & $\infty$ \\
\hline Arinaitwe-2009-UOA & 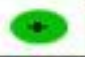 & $\oplus$ & 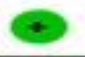 & C & $\oplus$ & $\rightarrow$ & $\oplus$ \\
\hline Bassat-2009-AFR & 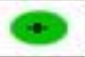 & $\oplus$ & 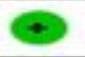 & $\theta$ & $\oplus$ & $\oplus$ & $?$ \\
\hline Borrmann-2011-KEN & $\oplus$ & 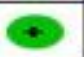 & $?$ & $\oplus$ & $\theta$ & $\oplus$ & $\leftarrow$ \\
\hline Gansane-2021-BNF & $\oplus$ & $?$ & $\ominus$ & $\oplus$ & $\oplus$ & $\oplus$ & $\oplus$ \\
\hline Grandesso-2018-NIR & $?$ & $?$ & $\Leftrightarrow$ & 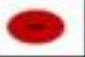 & 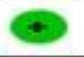 & $\oplus$ & $\oplus$ \\
\hline Kakuru-2014-UGA & $?$ & $?$ & $?$ & $?$ & $\oplus$ & $\oplus$ & + \\
\hline Kamya-2007-UGA & 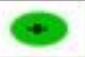 & $\oplus$ & 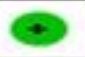 & $\oplus$ & + & 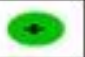 & + \\
\hline Mens-2008-KEN & $\odot$ & $?$ & $?$ & $\Leftrightarrow$ & $\oplus$ & $\oplus$ & 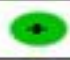 \\
\hline Nambozi-2011-ZAM & 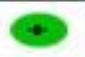 & 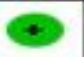 & $\oplus$ & 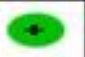 & $\oplus$ & $\rightarrow$ & $\oplus$ \\
\hline Nji-2015-CAM & 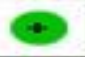 & 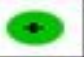 & + & $\oplus$ & $\oplus$ & $\oplus$ & + \\
\hline Ogutu-2014-KEN & $\oplus$ & $\oplus$ & 8 & 8 & $\oplus$ & 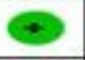 & + \\
\hline Onyamboko 2014 DRC & $\oplus$ & 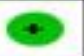 & $?$ & 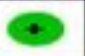 & $\oplus$ & $\rightarrow$ & $\oplus$ \\
\hline Sawa-2013-KEN & $\oplus$ & 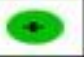 & $\Leftrightarrow$ & $\oplus$ & $\oplus$ & 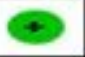 & $\oplus$ \\
\hline Ursing-2016-GUB & $\oplus$ & 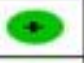 & $?$ & $?$ & $\oplus$ & 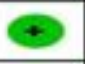 & + \\
\hline Yeka-2008-UGA & $\oplus$ & $\oplus$ & $\oplus$ & $\oplus$ & + & $\rightarrow$ & $\odot$ \\
\hline Үeka-2019-UGA & $\oplus$ & $\oplus$ & $\oplus$ & $\oplus$ & $\oplus$ & $\oplus$ & $\odot$ \\
\hline Zongo-2007-BNF & $\oplus$ & $\oplus$ & $\theta$ & $\theta$ & $\oplus$ & $\oplus$ & + \\
\hline
\end{tabular}

Figure 2

A summary of review authors' judgments about each risk of bias item for each included study. 


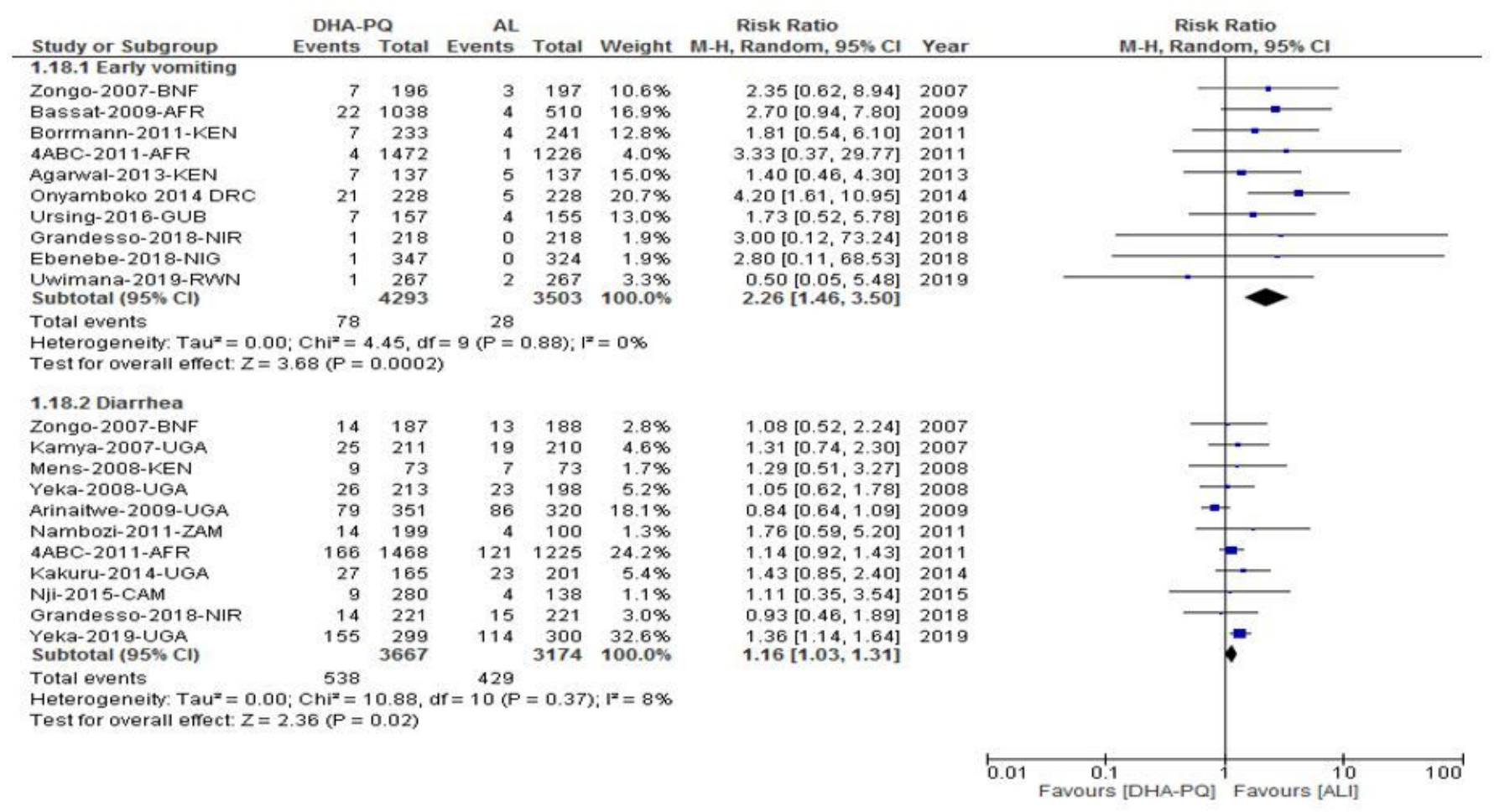

\section{Figure 3}

Forest plot of comparison with dihydroartemisinin-piperaquine and artemether-lumefantrine for treatment of uncomplicated plasmodium falciparum malaria among children in Africa on gastrointestinal adverse events. 
$\begin{array}{llll}\text { DHA.PQ } & \text { AL } & \text { Risk Ratio } & \text { Risk Ratio }\end{array}$ Study or Subgroup Events Total Events Total Weight M- $\mathrm{H}$, Random, $95 \% \mathrm{Cl}$ Year

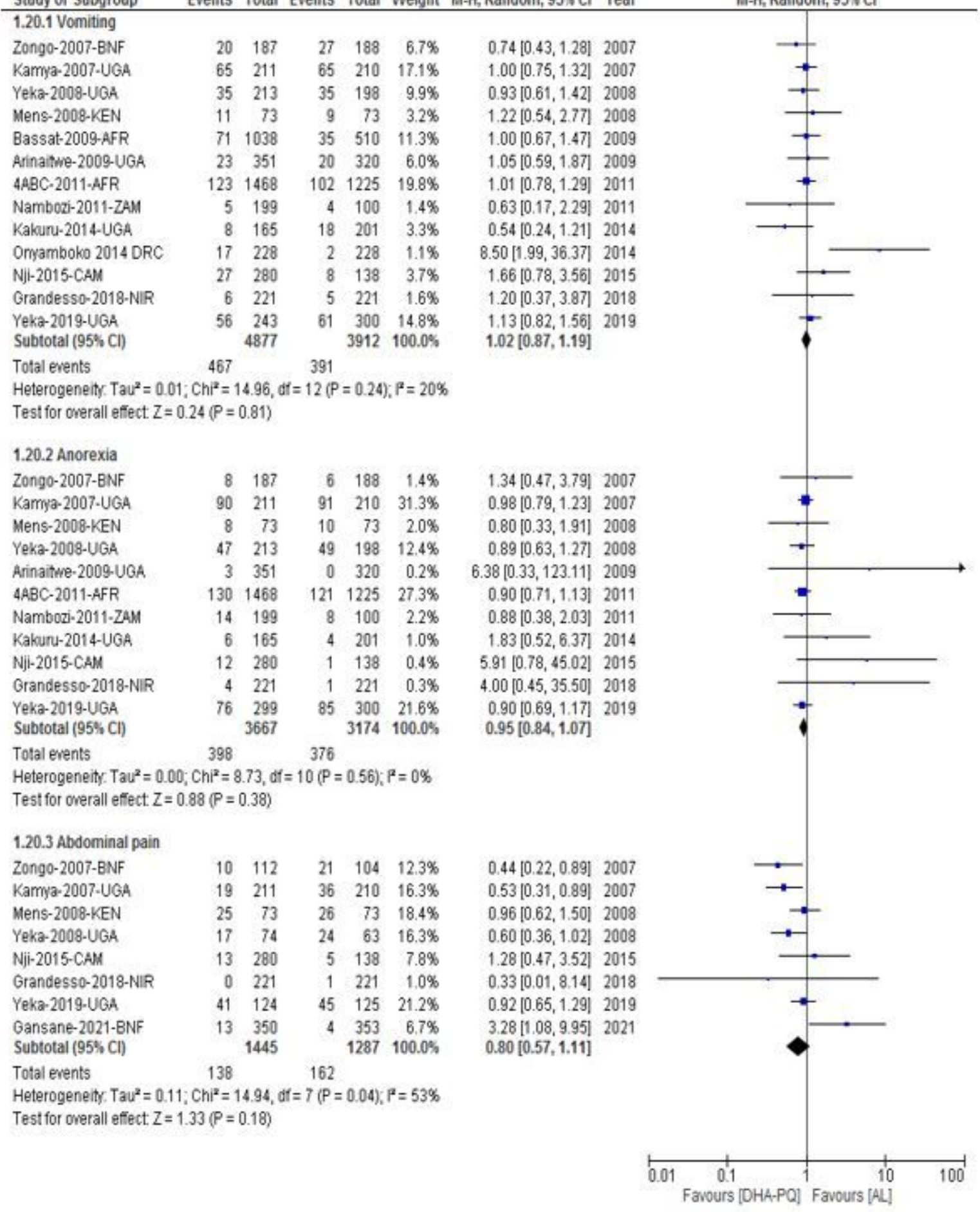

\section{Figure 4}

Forest plot of comparison: dihydroartemisinin-piperaquine versus artemether-lumefantrine for treatment of uncomplicated plasmodium falciparum malaria among children in Africa, outcome: Gastrointestinal adverse events. 
DHA.PQ

AL

Risk Ratio

Risk Ratio

Study or Subgroup

Events Total Events Total Weight M-H, Random, $95 \% \mathrm{Cl}$ Year

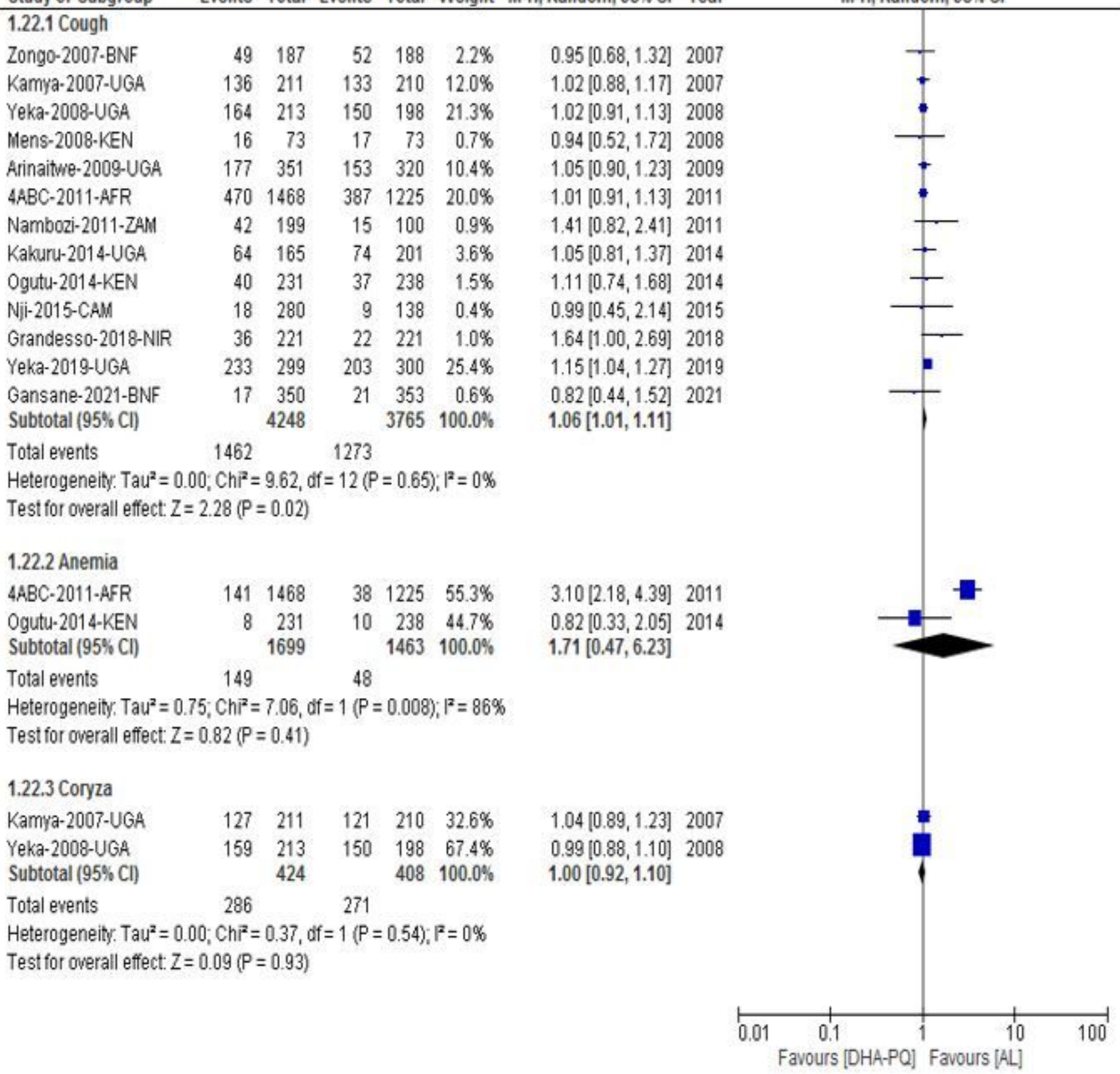

\section{Figure 5}

Forest plot of comparison between dihydroartemisinin-piperaquine and artemether-lumefantrine for treatment of uncomplicated plasmodium falciparum malaria among children in Africa on cardiorespiratory adverse events. 
DHA-PQ AL

AL Risk Ratio

Risk Ratio

Study or Subgroup Events Total Events Total Weight $\mathrm{M}-\mathrm{H}, \mathrm{Random}, 95 \% \mathrm{Cl}$ Year

1.23.1 weakness/malaise

Kamya-2007-UGA

$85 \quad 211$

103

$210 \quad 58.6 \%$

$0.82[0.66,1.02] 2007$

Zongo-2007-BNF

$5 \quad 187$

$\begin{array}{lll}3 & 188 & 1.3 \%\end{array}$

$1.68[0.41,6.91] 2007$

Mens-2008-KEN

$19 \quad 73$

$\begin{array}{lll}30 & 73 \quad 12.0 \%\end{array}$

$0.63[0.39,1.02] 2008$

Yeka-2008-UGA

$28 \quad 213$

$27 \quad 198 \quad 11.1 \%$

$0.96[0.59,1.58] 2008$

Arinaitwe-2009-UGA

1351

$\begin{array}{lll}0 & 320 & 0.3 \%\end{array}$

$2.74[0.11,66.92] 2009$

Kakunu-2014-UGA

2165

$2 \quad 201 \quad 0.7 \%$

$1.22[0.17,8.55] 2014$

Nji-2015-CAM

4280

$3138 \quad 1.2 \%$

$0.66[0.15,2.90] 2015$

Yeka-2019-UGA

$42 \quad 299$

$33 \quad 300 \quad 14.8 \%$

$1.28[0.83,1.96] 2019$

Subtotal $(95 \% \mathrm{Cl})$

1779

$1628100.0 \%$

$0.88[0.74,1.03]$

Total events $186 \quad 201$

Heterogeneity. $\mathrm{Tau}^{2}=0.00 ; \mathrm{Ch}^{2}=6.98, \mathrm{df}=7(\mathrm{P}=0.43) ; \mathrm{I}^{2}=0 \%$

Test for overall effect: $Z=1.58(P=0.11)$

1.23.2 Headache

Zongo-2007-BNF

Mens-2008-KEN

Yeka-2019-UGA

Subtotal $(95 \% \mathrm{Cl})$

$\begin{array}{rrrrr}11 & 111 & 22 & 104 & 27.2 \% \\ 43 & 73 & 37 & 73 & 41.4 \% \\ 18 & 115 & 24 & 122 & 31.4 \% \\ & 299 & & 299 & 100.0 \%\end{array}$

$0.47[0.24,0.92] 2007$

$1.16[0.86,1.56] 2008$

$0.80[0.46,1.39] 2019$

Total events

72

83

Heterogeneity. Tau $^{2}=0.16 ; \mathrm{Ch}^{2}=7.02, \mathrm{df}=2(\mathrm{P}=0.03) ; \mathrm{I}^{2}=72 \%$

Test for overall effect: $Z=0.79(P=0.43)$

M-H, Random, $95 \% \mathrm{Cl}$

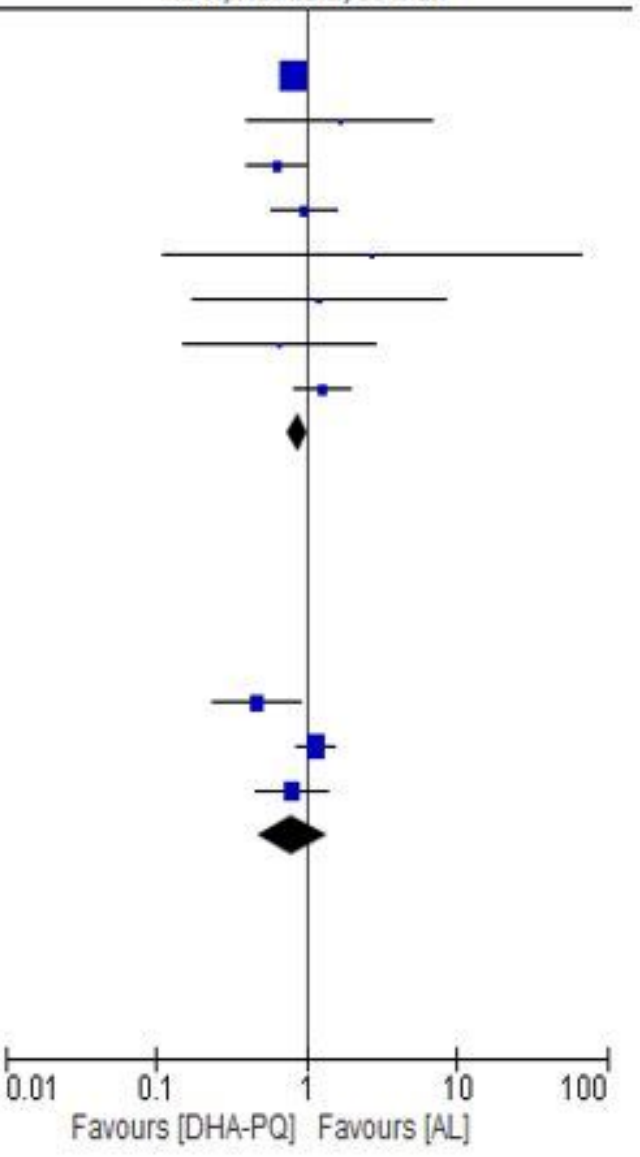

\section{Figure 6}

Forest plot of comparison: dihydroartemisinin-piperaquine versus artemether-lumefantrine for treatment of uncomplicated plasmodium falciparum malaria among children in Africa, outcome: Neuropsychiatry adverse event. 
DHA-PQ

AL

Risk Ratio

Risk Ratio

Study or Subgroup Events Total Events Total Weight M-H, Random, $95 \% \mathrm{Cl}$

\begin{tabular}{lrrrrrr}
\hline 1.24.1 Pruritus & & & & & & \\
Zongo-2007-BNF & 5 & 187 & 11 & 188 & $18.0 \%$ & $0.46[0.16,1.29]$ \\
Yeka-2019-UGA & 24 & 299 & 16 & 300 & $29.1 \%$ & $1.51[0.82,2.78]$ \\
Yeka-2008-UGA & 8 & 213 & 3 & 198 & $13.3 \%$ & $2.48[0.67,9.21]$ \\
Mens-2008-KEN & 4 & 73 & 3 & 73 & $11.4 \%$ & $1.33[0.31,5.75]$ \\
Kamya-2007-UGA & 14 & 211 & 22 & 210 & $28.2 \%$ & $0.63[0.33,1.20]$ \\
Subtotal (95\% CI) & & 983 & & 969 & $100.0 \%$ & $1.00[0.56,1.78]$ \\
Total events & 55 & & 55 & & &
\end{tabular}

Heterogeneity: $\operatorname{Tau}^{2}=0.20 ; \mathrm{Chi}^{2}=7.83, \mathrm{df}=4(\mathrm{P}=0.10) ; \mathrm{I}^{2}=49 \%$

Test for overall effect: $Z=0.01(P=0.99)$

\subsubsection{Skin rash}

Yeka-2019-UGA

Nji-2015-CAM

Gansane-2021-BNF

Subtotal $(95 \% \mathrm{Cl})$

Total events

$\begin{array}{rr}56 & 299 \\ 16 & 280 \\ 3 & 350 \\ & 929\end{array}$

$\begin{array}{rrr}42 & 300 & 86.3 \% \\ 4 & 138 & 10.0 \% \\ 2 & 353 & 3.6 \% \\ & 791 & 100.0 \%\end{array}$

$1.34[0.93,1.93]$

$1.97[0.67,5.79]$

$1.51[0.25,9.00]$

$1.40[0.99,1.96]$

Heterogeneity: Tau $^{2}=0.00 ; \mathrm{Ch}^{2}=0.46, \mathrm{df}=2(\mathrm{P}=0.79) ; \mathrm{I}^{2}=0 \%$

Test for overall effect: $Z=1.92(P=0.05)$

48

\section{Figure 7}

Forest plot of comparison: dihydroartemisinin-piperaquine versus artemether-lumefantrine for treatment of uncomplicated plasmodium falciparum malaria among children in Africa, outcome: Musculoskeletal/dermatological adverse events. 
$\begin{array}{llll}\text { DHA-PQ AL Risk Ratio Ratio } & \text { Risk Randomion }\end{array}$

Study or Subgroup Events Total Events Total Weight M-H, Random, $95 \% \mathrm{Cl}$ Year

$\begin{array}{lrrrrrll}\text { 1.25.1 Pyrexia } & & & & & & & \\ \text { 4ABC-2011-AFR } & 371 & 1468 & 339 & 1225 & 69.0 \% & 0.91[0.80,1.04] & 2011 \\ \text { Nambozi-2011-ZAM } & 24 & 199 & 14 & 100 & 2.9 \% & 0.86[0.47,1.59] & 2011 \\ \text { Nambozi-2011-ZAM } & 24 & 199 & 14 & 100 & 2.9 \% & 0.86[0.47,1.59] & 2011 \\ \text { Ogutu-2014-KEN } & 14 & 231 & 7 & 238 & 1.4 \% & 2.06[0.85,5.01] & 2014 \\ \text { Nji-2015-CAM } & 3 & 280 & 2 & 138 & 0.3 \% & 0.74[0.12,4.37] & 2015 \\ \text { Grandesso-2018-NIR } & 94 & 221 & 94 & 221 & 23.4 \% & 1.00[0.81,1.24] & 2018 \\ \text { Subtotal (95\% CI) } & & 2598 & & 2022 & 100.0 \% & 0.94[0.85,1.04]\end{array}$

Total events $\quad 530 \quad 470$

Heterogeneity: Tau $^{2}=0.00 ; \mathrm{Chi}^{2}=3.73, \mathrm{df}=5(\mathrm{P}=0.59) ; \mathrm{I}^{2}=0 \%$

Test for overall effect: $Z=1.17(P=0.24)$

1.25.2 Otitis media

Ogutu-2014-KEN

Gansane-2021-BNF

Subtotal $(95 \% \mathrm{CI})$

$\begin{array}{lllll}5 & 227 & 7 & 227 & 88.8 \%\end{array}$

$0.71[0.23,2.22] 2014$

$\begin{array}{lllll}0 & 350 & 1 & 353 & 11.2 \%\end{array}$

$0.34[0.01,8.22] 2021$

$0.66[0.23,1.91]$

Total events $\quad 5 \quad 8$

Heterogeneity: Tau $^{2}=0.00 ; \mathrm{Chi}^{2}=0.19, \mathrm{df}=1(P=0.66) ; \mathrm{I}^{2}=0 \%$

Test for overall effect: $Z=0.77(P=0.44)$

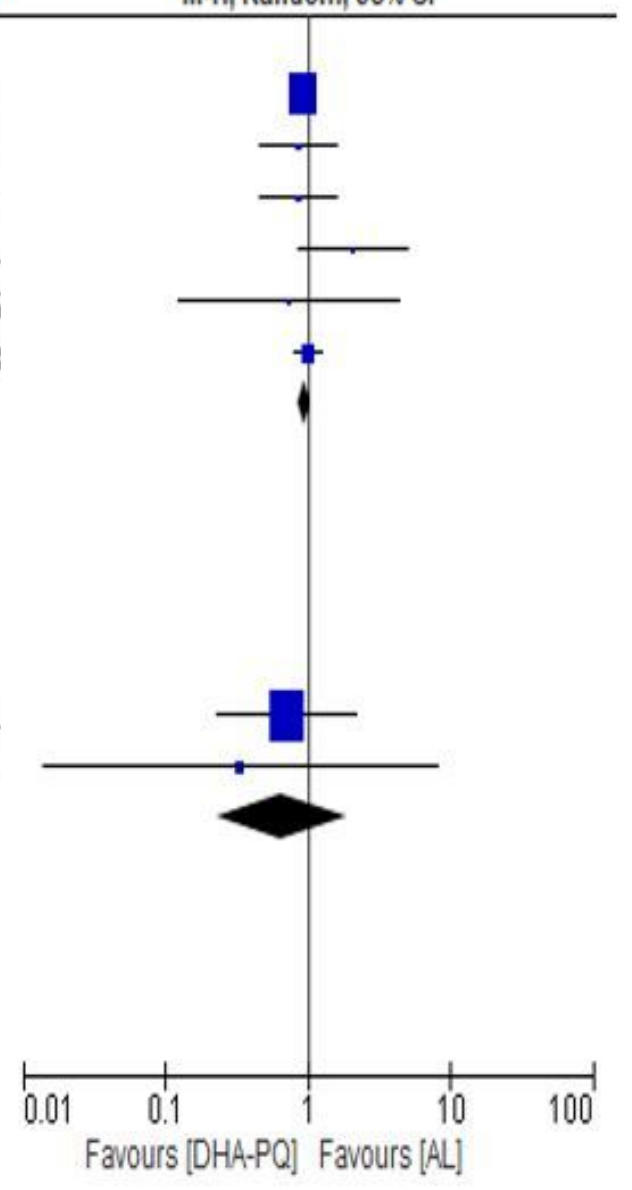

\section{Figure 8}

Forest plot of comparison: dihydroartemisinin-piperaquine versus artemether-lumefantrine for treatment of uncomplicated plasmodium falciparum malaria among children in Africa, outcome: Other Adverse events. 
$\begin{array}{llll}\text { DHA.PQ } & \text { AL Risk Ratio Risk Ratio }\end{array}$

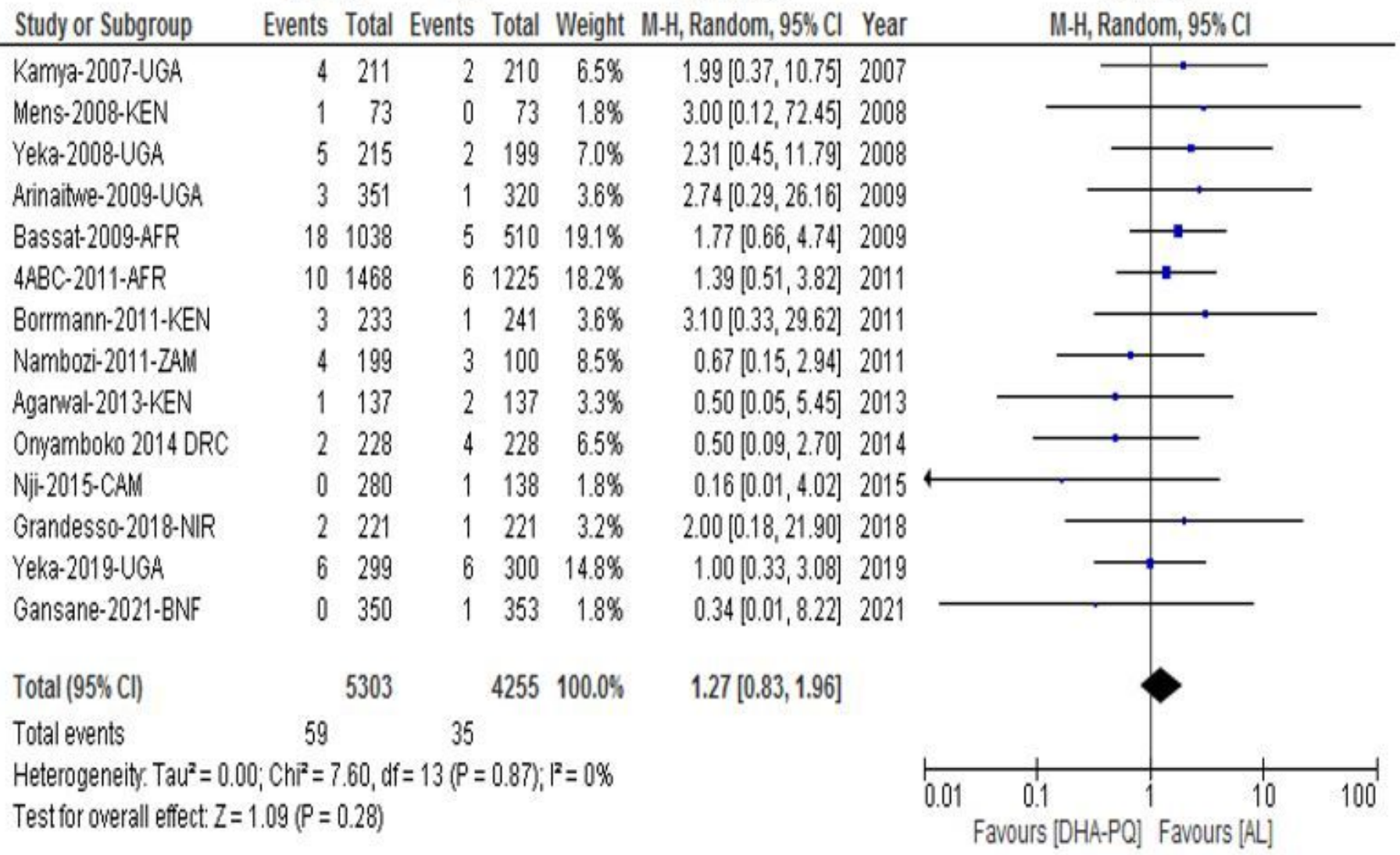

\section{Figure 9}

Forest plot of comparison between dihydroartemisinin-piperaquine and artemether-lumefantrine for treatment of uncomplicated plasmodium falciparum malaria among children in Africa on serious adverse event (including death).

\section{Supplementary Files}

This is a list of supplementary files associated with this preprint. Click to download.

- AdditionalfileS1.docx

- Additionalfiles2.docx

- AdditionalfileS3.docx

- Additionalfiles4.docx

- Additionalfiles5.docx

- Additionalfiles6.docx

- Additionalfiles7.docx

- Additionalfiles8.docx 